\title{
Quality of life study in Wound Care. Final report
}

Giuseppe Nebbioso, C. Albanese, F. Bonat, A. Botta, Giovanni Vito Corona, Cira Costagliola, Corrado Maria Durante, Ciro Falasconi, D. Foglietti, Francesco Giacinto, Pasquale Longobardi, Klarida Hoxha, Cosimo Maglio, Vincenzo Mattaliano, Massimo Menculini, Giovanni Battista Mosti, Carmela Orefice, Sonia Remafedi, Donatella Rossolini, Felice Tafuro, Francesco Petrella

Italian Association of Skin Ulcers, Turin, Italy

\section{INTRODUCTION}

In recent decades the aging of the population has led to an increase in chronic conditions responsible for various complications such as chronic skin lesions (CSL).

The data provided in the literature indicate an incidence of CSL up to 3\% but, in fact, little is known about the real impact of the different types of ulcers and we know even less about the quality of life and social status of the affected citizens.

By quality of life we refer to the subjective perception that an individual has of their physical and psychologicalemotional health, of the position they have in life in the context of the environment within which they live and in relation to their expectations and concerns.

It is a very broad concept that includes physical and psychological health, degree of independence, social relationships, personal beliefs and their relationship to the principal characteristics of their environment. Their health status is therefore influenced by so-called social determinants and their understanding and evaluation is critical to the development of new social and healthcare policies.

In order to evaluate the influence of social determinants on the genesis of CSL and the role that lesions have

Correspondence: Italian Association of Skin Ulcers, Via San Francesco da Paola 37, 10123 Turin, Italy.

Tel: +39.011.2446911 - Fax: +39.011.2446950

E-mail: info@aiuc.it

Key words: Chronic skin lesions; Aging; Physical-psychological condition; Italian Association of Skin Ulcers.

Received for publication: 31 December 2016.

Accepted for publication: 7 March 2017.

This work is licensed under a Creative Commons Attribution NonCommercial 4.0 License (CC BY-NC 4.0).

(C) Copyright G. Nebbioso et al., 2017

Licensee PAGEPress, Italy

Italian Journal of Wound Care 2017; 1(1):9-18

doi:10.4081/ijwc.2017.2 in the physical-psychological condition of patients, in January 2014 the AIUC (Italian Association of Skin Ulcers) and Simitu (Association for the rights of patients with chronic skin lesions) launched the study "Quality of life study in wound care", a survey on the quality of life of patients suffering from CSL, whose final results are presented in this publication.

\section{MATERIALS AND METHODS}

A questionnaire consisting of two parts, one for the investigation of social status and one (SF-12) on the influence that CSL have on the physical and psychological status, was handed to ambulatory patients on their first visit to outpatient clinics dedicated to treating such lesions.

The SF-12 (Short form health survey) is a multidimensional questionnaire aimed at investigating the perception of the physical and mental condition of individuals. The patient was explained the purpose and content of the questionnaire which was then filled out and returned before the visit began; with prior informed consent.

The section about social status requests information regarding: age, gender, residence, marital status, domestic partnership, level of education, occupational position of the patient and their share of the NHS co-payment expenses.

In the SF-12, the first six questions relate to health status (physical condition) and on the influence of the disease on daily activities. The remaining six questions investigate the emotional state and relate to family and the social environment.

\section{RESULTS}

The survey involved 450 patients, 273 women and 177 men between the ages of 22 and 92 with a higher incidence above 65 years of age (73\%) (Figure 1A and B).

Of those surveyed, $48 \%$ turned out to be single and/or widowed, of which $69 \%$ live alone or with an elderly spouse (Figure 2A and B).

An assessment of education level revealed that $6 \%$ were illiterate, $44 \%$ attended primary school, $24 \%$ grad- 
uated from middle school, while only $26 \%$ have a high school diploma or college degree (Figure 3).

Concerning employment, the vast majority of respondents $(77 \%)$ are retired (Figure 4).

Where the NHS is concerned, 91\% were completely exempt from co-payment (Figure 5).

Of those interviewed $65 \%$ evaluate their physical condition as not good (Figure 6).

$86 \%$ of respondents complain about a limited level of activities of moderate physical effort, while only $14 \%$ of patients say that they do not have these limitations (Figure 7).

$79 \%$ of patients report a reduction in activities even though they put effort in executing them (Figure 8).

The pathology affects the respondent's psychological

A

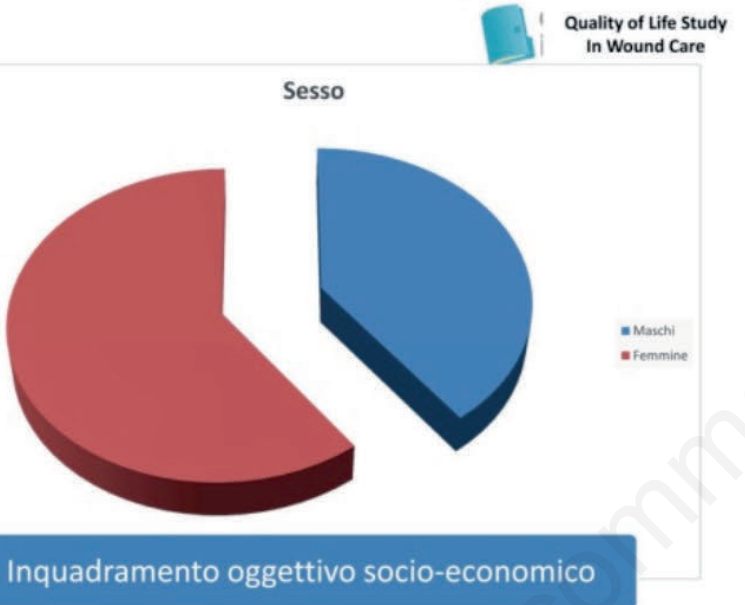

state: anxiety and depression result in reduced productivity and a lapse in concentration (63\%) (Figure 9).

$71 \%$ say that their emotional state has adversely affected daily activities (Figure 10).

Pain is present in a significant way in about $50 \%$ of the respondents, negatively influencing their daily lives (Figure 11).

In evaluating the patient's psychological status, we see a negative trend as parameters such as calm, serenity, energy tend to decrease with an increase in the feeling of discouragement and sadness (Figure 12).

$75 \%$ report that their physical and mental condition interfered negatively in their social activities, with their family or friends (Figure 13).
B

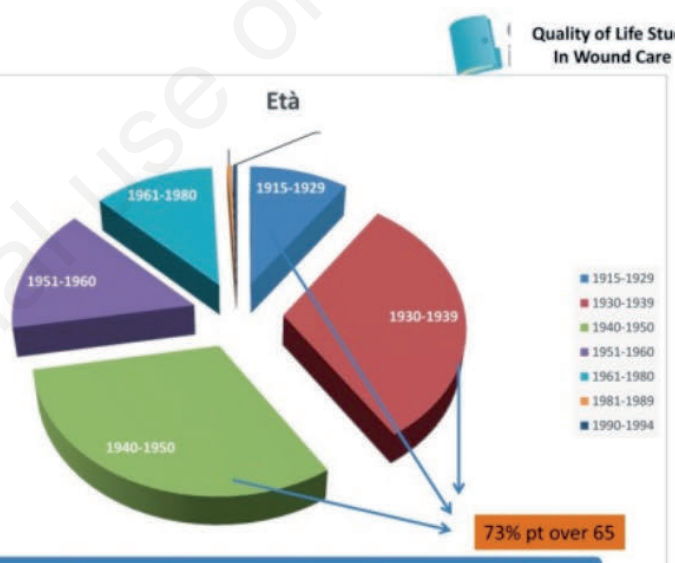

Inquadramento oggettivo socio-economico

Figure 1.

A

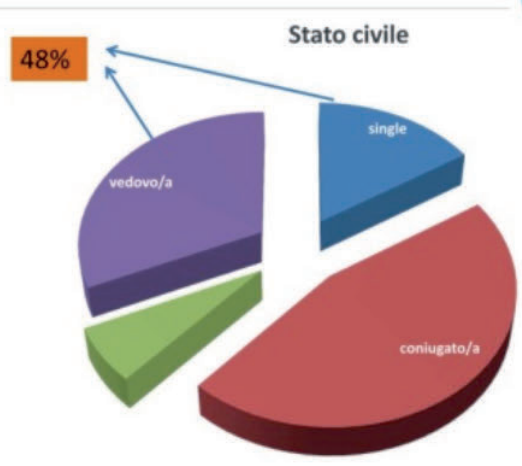

Inquadramento oggettivo socio-

economico
Quality of Life Study In Wound Care

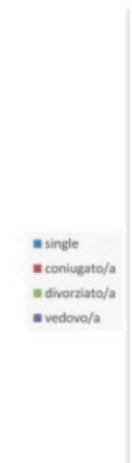

B

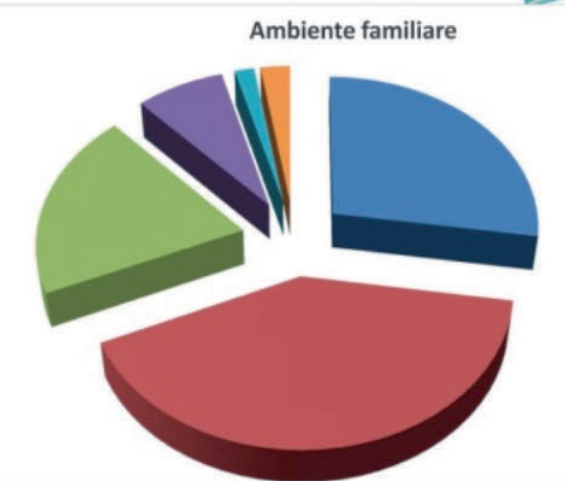

Inquadramento oggettivo socio-economico

Figure 2. 


\section{DISCUSSION}

A majority of respondents were female and thus the data may be related either to the greater incidence of some ulcers in women (e.g. venous and vasculitic) or to the longer life expectancy of women considering that CSL manifest themselves in old age.

Regarding the age of the patients, most are between the ages of 65 and $80(63 \%)$ while $10 \%$ of patients are over 84 . This figure is aligned with data found in the literature that shows a higher incidence of lesions over 65 years of age.

Nearly half of respondents are widowed or single and this negatively affects the healing of the injury since the lack of a family and relational environment isolates the patient in managing their illness, also complicating access to healthcare facilities that are often far from home.

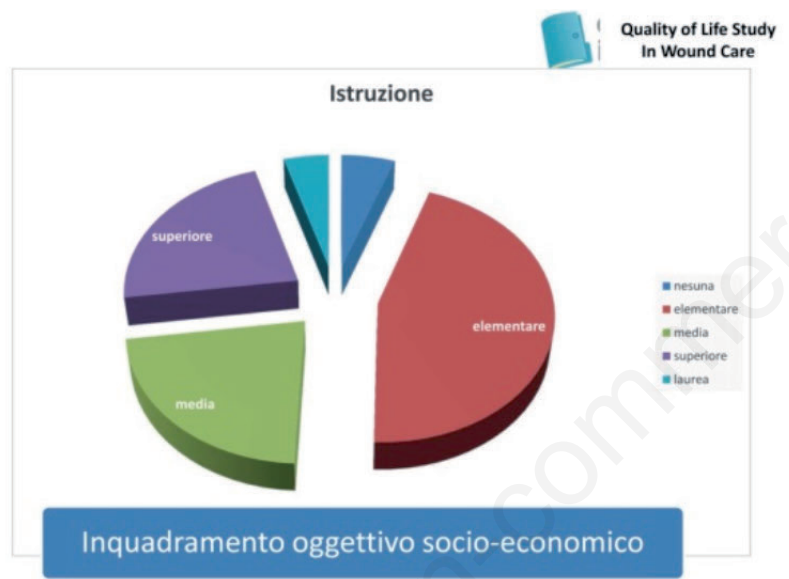

Figure 3.

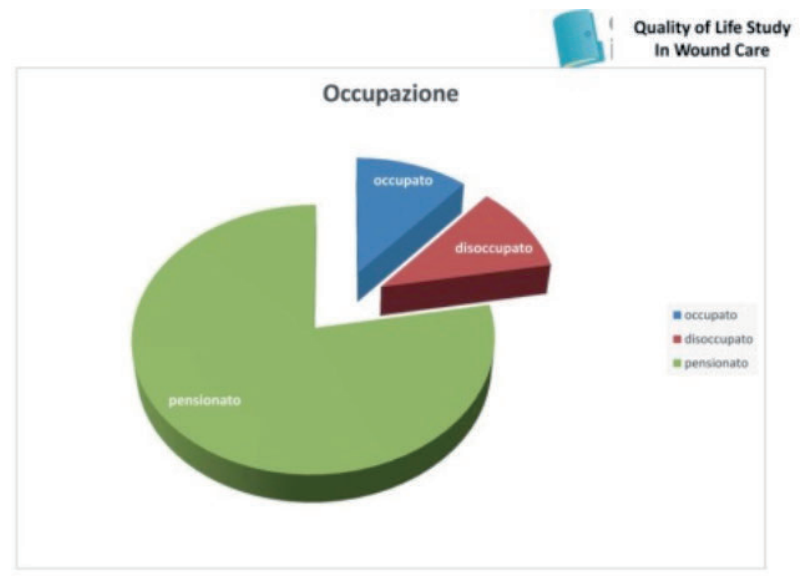

Figure 4.

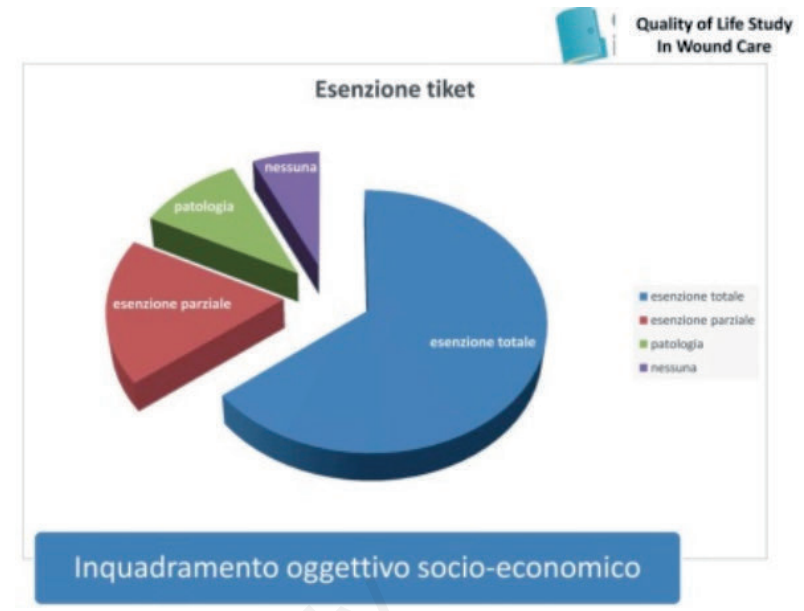

Figure 5.

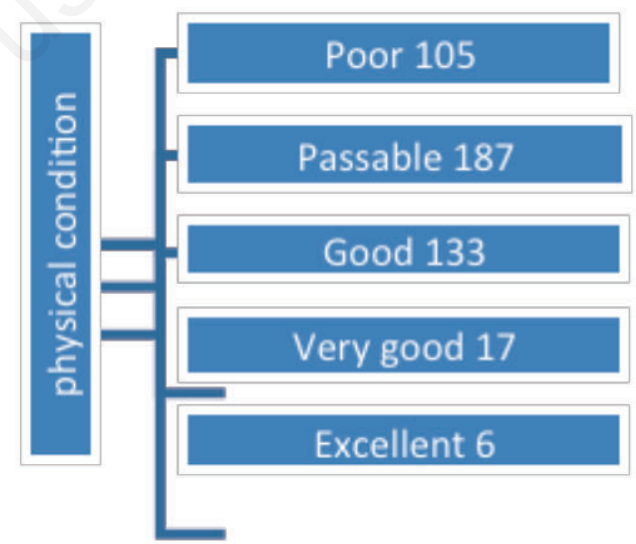

Figure 6.

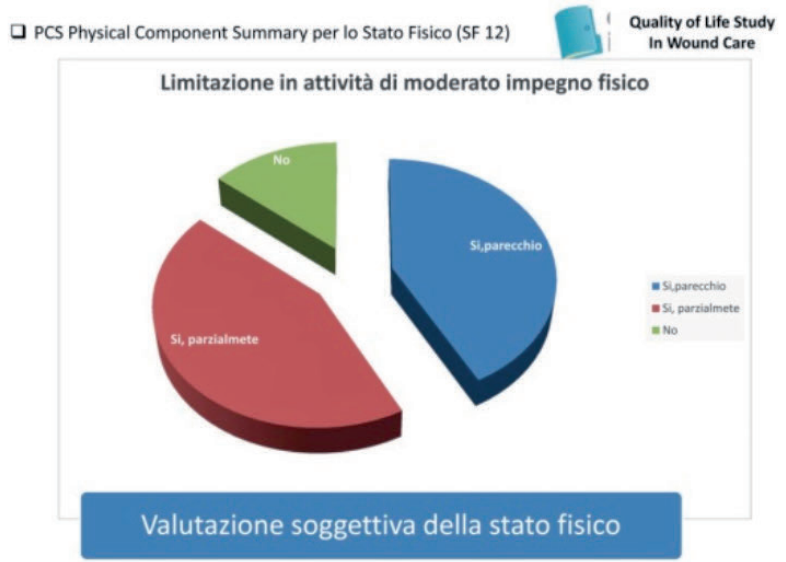

Figure 7. 
a PCS Physical Component Summary per lo Stato Fisico (SF 12) A causa della sua condizione fisica ha reso meno $\mathrm{d}$ quanto avrebbe voluto?

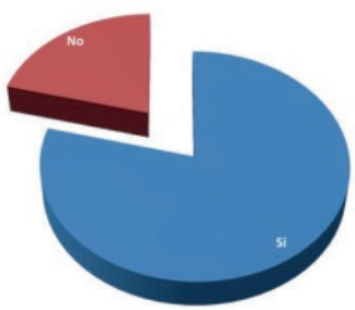

Valutazione soggettiva della stato fisico

Figure 8.

a MCS MentalComponent Summary per lo Stato mentale Quality of Life Study In Wound Care

A causa del suo stato emotivo (ansia-depressione) ha avuto un calo di concentrazione?

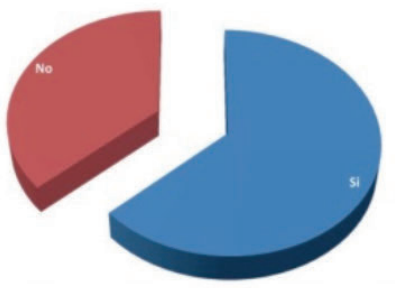

Valutazione soggettiva della stato psichico

Figure 9.

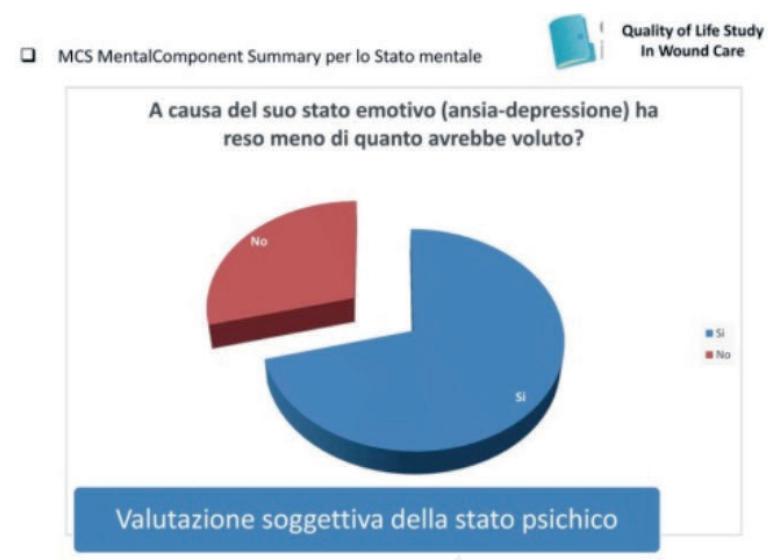

Figure 10.

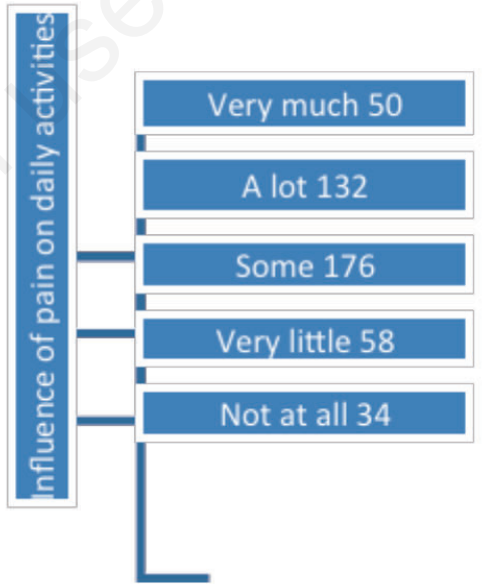

Figure 11.

\section{You feel calm and serene}

- Never 22

- Almost never 96

- Part of the time 136

- Often 49

-Almost always 110

-Always 36

\section{You feel full of energy}

- Never 41

- Almost never 121

- Part of the time 143

- Often 41

-Almost always 62

-Always 11

\section{You feel discouraged} and sad

- Never 38

- Almost never 95

- Part of the time 132

- Often 60

- Almost always 89

-Always 35

Figure 12. 
Among social determinants, educational level has the greatest effect upon the probability of healing. An analysis of the survey data clearly shows that individuals with a low level of education suffer more frequently from lesions.

The figure leaves open various interpretation possibilities concerning patient age and poor schooling in a specific period in our history or how living in an environment with precarious and poor social conditions hampers the prevention and treatment of lesions.

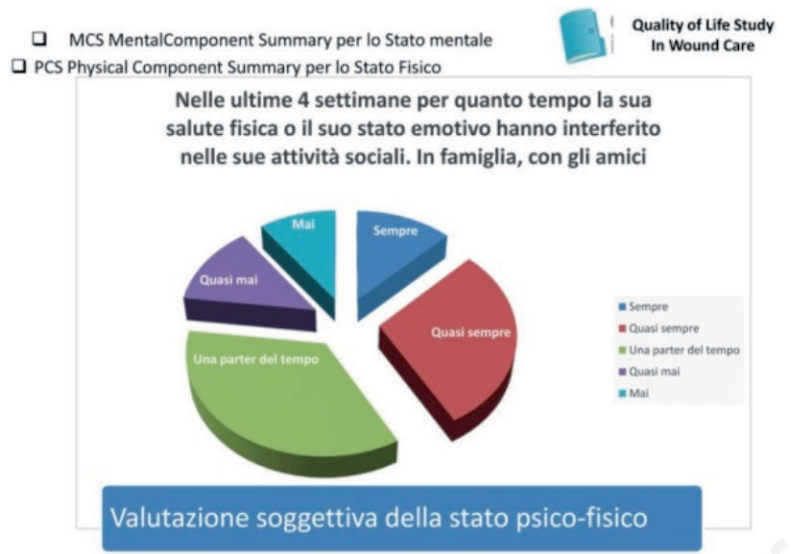

Figure 13.
The vast majority of respondents are retired or unemployed in deep economic difficulties with very low or zero income facing a pathology that is not covered by essential care levels and thus not adequately supported by the NHS.

In support of what has been said for the occupation of respondents, $91 \%$ are exempt from co-payment. In fact, a co-payment exemption is granted to people with very low income but does not cover materials or medications used for the management of lesions. Expenses which are ultimately borne by the patients themselves.

The presence of lesions negatively affects the physical and psychological condition of the patient. Normal daily activities are negatively affected in the same way as psychological status by a lapse in concentration at work or in other activities accentuated by the presence of pain.

\section{CONCLUSIONS}

CSL are a complication of chronic pathologies with a variety of causes that are difficult to correctly diagnose and which occur more frequently in senior citizens who are alone with low education and in precarious physical condition whose physical status and psychological condition are negatively affected by the lesion. Anxiety, depression and feelings of discouragement push the patient toward isolation and marginalization in the family and social environment resulting in a progressive deterioration of quality of life. 